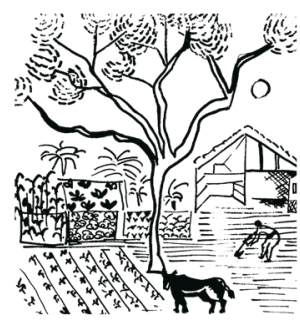

\title{
Co-educação, reconhecimento e saberes tradicionais: um estudo com mulheres assentadas em Araraquara-SP
}

\author{
Thauana Paiva de Souza Gomes ${ }^{1}$ \\ Vera Lúcia Silveira Botta Ferrante ${ }^{2}$ \\ Dulce Consuelo Andreatta Whitaker ${ }^{3}$
}

\begin{abstract}
Resumo: O presente trabalho é parte de um projeto intitulado "Construindo elos entre Agroecologia e Comunidades rurais: desafios da relação entre Ensino, Pesquisa e Extensão" o qual reflete ações do NUPEDOR- Núcleo de Pesquisa e Documentação Rural- voltadas à problemática da agricultura familiar e de assentamentos rurais. O presente recorte destaca o importante papel de mulheres assentadas no processo de conservação ambiental, permanência e transferência de saberes agroecológicos. A metodologia toma como parâmetros princípios da pesquisa-ação com a realização de diagnósticos participativos, dias de campo, capacitações, desenvolvimento e fortalecimento de tecnologias sociais a reforçar a continuidade da proposta de diálogo e interação com as comunidades investigadas. Os principais resultados verificados, se fazem no processo de diálogo e construção conjunto do conhecimento, entre as práticas tradicionais e o conhecimento científico que no processo que designamos como co-educação possibilitam a manutenção e o fortalecimento de grupos de mulheres comprometidas com os princípios da produção e da comercialização de base ecológica a partir de resgate e transferência de saberes ecológicos.
\end{abstract}

Palavras-Chave: Agroecologia; Educação; Saberes tradicionais; Extensão; Assentamentos; Mulheres.

\section{CO-EDUCATION, RECOGNITION AND TRADITIONAL KNOWLEDGE: A STUDY WITH WOMEN BASED IN ARARAQUARA- SP}

ABSTRACT: The present work is part of a project entitled "Building links between Agroecology and Rural Communities: Challenges of the relationship between Teaching, Research and Extension" which reflects actions of NUPEDOR - Rural Research and Documentation Nucleus - focused on family farming and agriculture. rural settlements. This paper highlights the important role of settled women in the process of environmental conservation, permanence and transfer of agroecological knowledge. The methodology takes as its parameters the principles of action research with the conduction of participatory diagnoses, field days, training, development and strengthening of social technologies to reinforce the continuity of the proposal of dialogue and interaction with the investigated communities. The main results are in the process of dialogue and joint construction of knowledge, between traditional practices and scientific knowledge that in the

\footnotetext{
${ }^{1}$ Pesquisadora do Nupedor (Núcleo de Pesquisa e Documentação Rural), Docente e coordenadora dos cursos de Sociologia, Teologia e Ensino Religioso do Centro Universitário Estácio de Ribeirão Preto. E-mail: thauanap@gmail.com

${ }^{2}$ Coordenadora e Docente do PPG em Desenvolvimento Territorial e Meio Ambiente da Universidade de Araraquara (Uniara).E-mail:dtma@uniara.com.br

${ }^{3}$ Mestre e Doutora em Sociologia. Professora colaboradora (aposentada) da Faculdade de Ciências e Letras de Araraquara (FCLAR/UNESP). Professora do Programa de Pós-Graducação em Desenvolvimento Territorial e Meio Ambiente da Universidade de Araraquara-(Uniara).
} 
process we call co-education enable the maintenance and strengthening of groups of women committed to the principles of production. and ecologically based marketing through the rescue and transfer of ecological knowledge

KeYwOrds: Agroecology; Education, Traditional Knowledge, Extension; Settlements, Women.

\section{INTRODUÇÃO}

Tomando por base a ênfase nas atividades de agricultura de base ecológica, que extrapola uma abordagem tecnicista, levando em conta experiências anteriores de estudos em assentamentos rurais, via de regra, sustentadas pela pesquisa-ação, propõe-se a analisar o papel das mulheres na conservação e transferência de saberes agroecológicos. Estimulando a prática da produção diversificada e não convencional no território da região Central do Estado de São Paulo. O mesmo, caracterizado pela produção de monocultivos de cana-de-açúcar e laranja, intensivos no uso de agrotóxicos e sistemas produtivos com baixa demanda de força de trabalho. Realidade que traz consequências negativas para a segurança alimentar e o balanço energético da produção de alimentos, já que tais monocultivos tendem a expulsar a agricultura voltada à produção de alimentos implicando em perda de hábitos alimentares locais. Também o desmatamento tem influência sobre o microclima regional, a conservação de solos e a conservação dos recursos hídricos (FERRANTE et al., 2018).

O conceito de agroecologia aqui colocado parte do princípio de que a Agroecologia não é um sistema de produção, mas um enfoque teórico- metodológico, uma ciência de síntese entre várias outras ciências, não apenas entre agronomia e ecologia, como a palavra sugere (GLIESSMAN, 2000; SEVILLA GUZMÁN, 2002). Acrescente-se que os conhecimentos das comunidades ligadas à terra e ao meio ambiente, no processo de construção conjunta do conhecimento, podem através de suas ações, permitir a transformação social e transição agroecológica.

Assim sendo, o enfoque agroecológico traz consigo as ferramentas teóricas e metodológicas que auxiliam se considerar, de forma holística e sistêmica, as seis dimensões da sustentabilidade, ou seja: a ecológica, a econômica, a social, a cultural, a política e a ética (CAPORAL; COSTABEBER, 2009). Desta forma, o conceito é amplo, pois pretende compreender toda a complexidade de processos biológicos e tecnológicos, socioeconômicos e políticos, abrangendo a produção e a circulação dos bens produzidos, até sua chegada aos consumidores (SEVILLA GUZMÁN, 2002). 
Se partirmos de uma análise multifacetada da agricultura atual teríamos, que na dimensão energética, o padrão tecnológico agrícola tem evoluído de sistemas de mão-de-obra intensivos para processos crescentemente artificializados e mecanizados, obedecendo à lógica capitalista de incremento do consumo de energia e insumos industriais, e de aumento da produtividade do trabalho (RAPPAPORT, 1971; PIMENTE, 1980; GLIESSMAN, 2000).

Na esfera ecológica, a adoção de um modelo de capital intensivo e com reduzida biodiversidade causa problemas diretamente associados à base dos recursos flora, solo e água, que incluem a erradicação da flora, a erosão, a queda da produtividade, o esgotamento do solo e da reserva de nutrientes, a redução da reserva de água nos solos, a poluição das águas superficiais e subterrâneas.

A perda da agrobiodiversidade é um fator que preocupa muito no cenário específico do assentamento estudado, cenário, com forte presença da monocultura de cana, eucalipto, soja e milho. Estes dois últimos, majoritariamente transgênicos, inclusive nas áreas de assentamentos e agricultura familiar, têm levado à contaminação genética do milho crioulo e à erosão da biodiversidade local (FERMENT et al., 2015; FERNANDES; FERRAZ; MELGAREJO, 2013; KAGEYAMA, 2009).

No caso específico da dimensão sócio-cultural das comunidades rurais ou povos tradicionais, teríamos um processo de perda e deslocamento dos conhecimentos adquiridos durante séculos através da relação imediata e constante com a natureza; para um saber artificializado, que tem consequências tanto para seus modos de vidas, como para diversidade das espécies locais, as quais substituídas por sementes melhoradas e modificadas, alteram o padrão cultural das dietas destas populações e impossibilitam a conservação inclusive de plantas comuns de cada comunidade. $\mathrm{O}$ impacto da substituição dos conhecimentos tradicionais de cada região/localidade/ solo por um pacote "tecnocientífico" proposto por grande corporações agrícolas, vai aos poucos anulando não apenas saberes específicos, mas efetivamente modos de vida, práticas sociais, espécies de todos os tipos, ecossistemas (GOMES, 2018). No caso dos assentamentos rurais, suas trajetórias marcadas pelo incentivo a uma agricultura de base convencional, por parte do mercado e dos agentes de assistência técnica, sem que fosse incentivado o aproveitamento dos recursos locais e outras práticas agroecológicas de manejo. Neste contexto, o papel das mulheres nos assentamentos com relação ao meio ambiente destaca-se pela importante relação no processo de conservação ambiental, permanência e transferência de saberes agroecológicos.

Os saberes tradicionais e os conhecimentos adquiridos de forma geracional com a vivência com a natureza, predominante nas atividades femininas, são substituídos 
por práticas artificializadas e sintéticas. Vale ponderar que parte destes pequenos produtores não percebe os impactos e males dos usos destas práticas, ou mesmo os desconhece, por falta de informação, mas uma outra parcela, consciente de todos os problemas trazidos pelo uso de pesticidas e inseticidas, continua a executar tais práticas, iludidos pelas promessas de produtividade (GOMES, 2019).Neste aspecto, o papel feminino é duplamente importante: primeiro, por ser, em grande medida, responsável pela permanência da resistência de práticas alternativas frente ao sistema da agricultura convencional e, segundo, pelo fato das mulheres manterem vivos e repassarem conhecimentos sobre saúde, criação e meio ambiente mais sustentável às novas gerações.

Muitas das práticas naturais que a ciência tem chamado de Agroecologia têm se conservado e sido praticadas em quintais, áreas da agrovila, pomares, sítios, hortinhas, lugares nos quais a figura feminina prevalece como ponto central na organização e cuidado, no sentido mais afetivo desta palavra (GOMES, 2015).

A produção nos moldes agroecológicos necessita de um conhecimento sobre a complexidade das interações nos agroecossistemas, e da relação homem-sociedadenatureza, o mesmo ocorrendo com os processos de transição agroecológica. As mulheres em seu processo diário de cuidados com a terra, criação e quintais e produção no embolado de práticas e acumulado de espécies vão mantendo e multiplicando os conhecimentos sobre conservação e proteção ambiental. Que a ciência designa como ecológicas, sustentáveis ou agroecológicas.

Sob esta ótica os processos de pesquisa-ação junto às mulheres assentadas permitem um processo de co-educação, ou seja, ao mesmo tempo em que se propõem capacitações, reflexões e manejos sustentáveis verifica-se entre essas mulheres um processo de conservação tanto de práticas como de inúmeras espécies. O processo conjunto de construção de práticas e conhecimentos agroecológicos se estrutura em forma de troca, valorização de saberes que finalmente resulta em um processo de resistência.

A partir destes aspectos passamos a estudar nos assentamentos sob a perspectiva longitudinal que confirma o princípio da multidimensionalidade e da complexidade da realidade destes locais, apresentando, entre outros aspectos contraditórios, a resistência por parte das mulheres na conservação ambiental frente ao uso de agrotóxicos. Do ponto de vista analítico, temos assumido que a relação dos assentamentos com o desenvolvimento territorial não é linear, mas pautada por uma trama de tensões sociais, que se expressa tanto objetiva como subjetivamente, no modo de vida, nas formas de inserção dos assentados em contextos regionais, nos bloqueios enfrentados na área da comercialização, nos vieses de gênero que 
muitas vezes excluem as mulheres das decisões sobre o presente e o futuro dos assentamentos, na pouca eficácia das políticas públicas, dentre outros fatores.

Por outro lado, coloca-se a necessidade de compreensão dos contrapontos representados pelos assentamentos frente aos constrangimentos estruturais que a sociedade impõe, através do mercado e do Estado. Em continuidade a essa linha de interpretação, é fundamental discutir continuadamente a importância de se aprofundar as relações entre ensino, pesquisa e extensão no processo co-educativo e formativo dos envolvidos no processo. Diante desta perspectiva, as iniciativas de caráter agroecológico das mulheres em seu processo de transferência de saberes e práticas passaram a ter uma importância significativa na compreensão da agricultura mais sustentável, a partir dos contrapontos ao modelo do agronegócio.

\section{Metodologia}

Diante da diversidade dos assentamentos rurais e da complexidade da transição agroecológica, a construção de metodologias participativas com vistas à superação dos problemas da realidade local é necessária, porém, é um desafio colocado ao conhecimento cientifico e a sua interlocução com a comunidade.

A extensão rural predominante, calcada na visão cartesiana e no difusionismo tecnológico, não dá conta da construção de um novo paradigma para o desenvolvimento rural, onde o conhecimento tradicional do agricultor familiar e em especial das mulheres assentadas e seus aspectos culturais, sociais, econômicos, políticos e ecológicos devem compor a relação estabelecida com o saber científico.

Para Gastal et al. (2002) na metodologia participativa se juntam vários métodos de natureza interativa, usando diversos instrumentos específicos, e constitui-se num convite à ação e ao aprendizado conjunto, possibilitando maior acesso ao poder decisório (empoderamento das pessoas envolvidas e da organização). O método participativo é um processo no qual a troca de informações ocorre entre todos envolvidos, internaliza-se os problemas e potencialidades principais de forma coletiva, o que gera interação dos envolvidos, provocando e apoiando o processo de mudança comportamental de cada um e do grupo como um todo.

Esse fazer pedagógico comum, coletivo e apoiado em conhecimentos tradicionais é visto como importante estratégia de valorização das mulheres envolvidas e também uma ferramenta de assimilação e interiorização de práticas agroecológicas.

A escolha dos sujeitos partiu inicialmente da ideia da construção de um inventário do conhecimento de mulheres sobre as ervas medicinais e sua utilização no cotidiano, o qual se estruturou através de uma pirâmide de informações iniciada na cooperativa - que indicou as principais mulheres produtoras, depois alguns outros agentes 
envolvidos, que se inseriram no projeto de processamento de ervas medicinais.

Assim, iniciamos um trabalho de levantamento dos sujeitos da pesquisa de forma que pudéssemos adquirir o máximo de informações ligadas ao conhecimento das ervas no assentamento. Desta maneira, foram escolhidas 25 mulheres pela relação com a cooperativa e sua proximidade com o interesse pelas plantas medicinais e/ou ainda pelo conhecimento e produção. Das 25 mulheres listadas, foram entrevistadas 20 , e, destas, ficaram 16 mulheres que aceitaram participar do projeto de pesquisa.

Foram realizadas entrevistas com visitas aos lotes com o intuito de elaborar um rol de informações que nos dessem elementos para mapear as práticas e saberes ecológicos das mulheres transmitidas aos grupos mais jovens. Cada entrevista realizada tornava-se uma orientação para a próxima, a partir da composição do nome previamente estabelecido e da indicação da própria entrevistada.

Concomitantemente foram realizados, com o grupo de mulheres, cursos de capacitação em que elas trocavam conhecimentos e aprofundavam outros sobre os processos e métodos orgânicos e agroecológicos de produção, formas de processamento de ervas, formas de usos.

\section{Perfil das MulHeres PeSQuisadas: de QUe MulHeres falamos?}

As mulheres rurais dos assentamentos da região de Araraquara vêm apresentando um papel protagonista na esfera social, que se inicia na luta pela terra, com lideranças importantes, como na política atual. Basta verificarmos que, nos últimos tempos, sobressaíram-se em cargos de vereadoras, coordenadoras, delegadas, entre outras situações de destaque. Isso se deve à nova realidade que se impõe, fruto de lutas sociais entre eles mobilizados pelo movimento feminista. Por isso, encontramos as mulheres assentadas em esferas políticas e produtivas em busca não de sua autoafirmação, mas da consolidação das conquistas previstas até aqui e de outras que ainda se desejam. O destaque ainda se dá à maior escolaridade e capacitação, que conduziram a alternativas produtivas individuais, coletivas e também a empregos no rural e no urbano.

No que se refere propriamente ao trabalho realizado nos quintais e nas hortas, vale salientar que grande parte da produção é destinada ao autoconsumo, mas tem se tornado, em grande medida, parte da renda que é comercializada em programas institucionais e feiras, além da inserção em rede de trocas de alimentos no interior dos próprios assentamentos. Sobre isso, Ferrante (2007, p.22) salienta:

além de reforçar a atuação das mulheres na esfera produtiva desses alimentos, salienta-se que majoritariamente são elas que os preparam para o consumo da família e realizam o processamento caseiro/artesanal, que pode ser uma 
alternativa de produção e comercialização. A responsabilidade compartilhada entre homens e mulheres na horticultura é simbólica e interessante porque esta é a produção vegetal mais intensiva em mão-de-obra e a que mais se insere no mercado institucional (...) Analisando a questão dos responsáveis pelas criações descritas acima, observamos a grande importância do papel da mulher na condução de todo processo produtivo das pequenas criações (aves e suínos) e também na produção de leite.

A participação das mulheres tem representado a maioria nas agroindústrias caseiras - em 60\% dos casos- essencialmente na produção de alimentos, o que reforça o importante papel da produção e processamento diversos de alimentos (FERRANTE, 2007). Nos últimos tempos, este tipo de processamento tem ganhado ainda mais força nas inúmeras associações e organizações femininas que tem se estruturado no interior do assentamento Bela Vista e Monte Alegre, como evidenciado no quadro 1.

Quadro 1- Associações de mulheres ou com papel principal da figura feminina nos assentamentos da região de Araraquara.

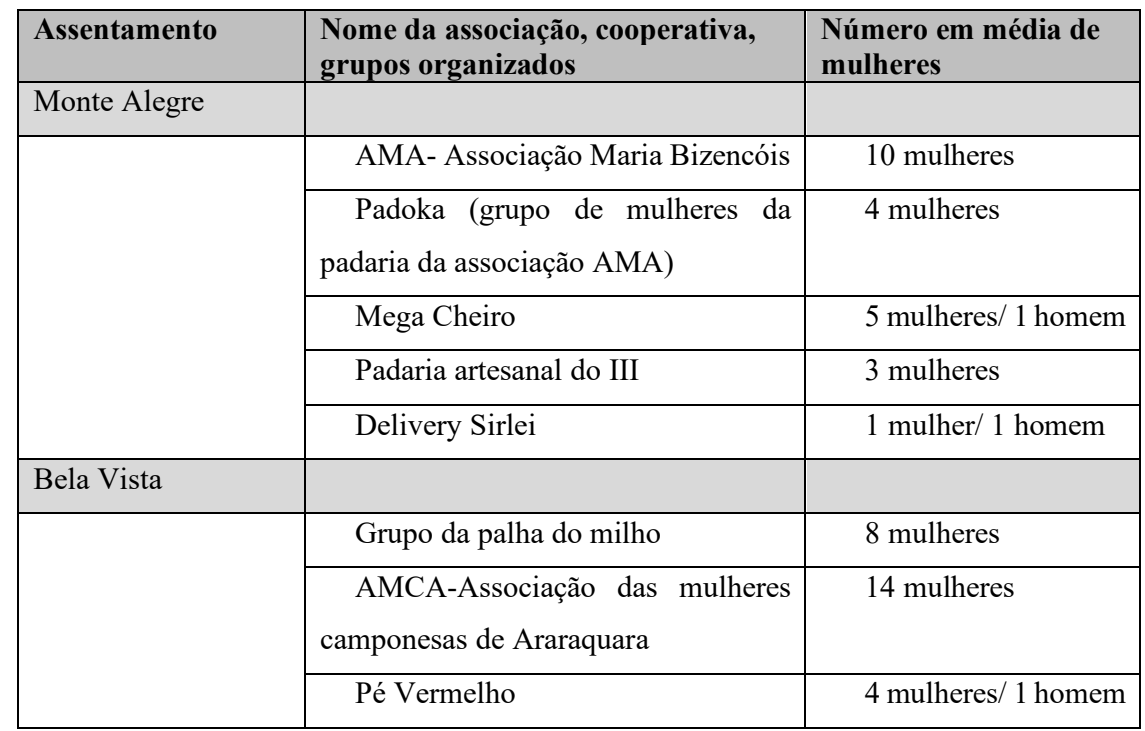

Fonte: GOMES,2018. 
Como podemos identificar, existem muitos grupos, formais ou não formalizados, mas que têm diferentes atuações nos assentamentos, com destaque para processamento e agroindustrialização de alimentos. Segundo Ferrante (2007, p.23):

as atividades não agrícolas contam nas estratégias de reprodução social postas em prática pelos assentados. No entanto, reflexões que apontam a maior importância das atividades não agrícolas na permanência dos assentados na terra e no futuro dos assentamentos não se aplicam nesta região. Reafirmamos, tais dados reforçam as reflexões que têm apontado a importância do autoconsumo no modo de vida dos assentados, reafirmando as análises que apontavam a necessidade de inserir o autoconsumo nas ponderações sobre renda, o que exige a sua abordagem igualmente pelo prisma não diretamente monetário, já que o consumo desses produtos representa tanto uma economia monetária como uma renda a mais pela comercialização do excedente. A visibilidade do autoconsumo considerando-se todas essas produções agrícolas, a transformação caseira e atividades não agrícolas - é um caminho para a valorização da importância do trabalho feminino.

Além disso, salientam-se ainda atividades importantes das mulheres nas cooperativas, sendo elas articuladoras das ações, ou responsáveis por coordenação de atividades administrativas. Neste caso, os cargos de presidência dos homens passam por fachadas, já que a maior parte das decisões é consultada e passa pela resolução destas mulheres ${ }^{4}$.

Um exemplo disso é a articulação do grupo de ervas aqui evidenciado, que passa pela figura da ex-secretária da cooperativa, e que, junto à pesquisadora, organizou as visitas às mulheres interessadas no projeto de processamento e secagem de ervas. O papel dela na cooperativa advinha desde a organização de documentação, como articulação de projetos e compras com prefeituras e/ou parceiros comerciais (GOMES, 2018).

A saída dela da cooperativa envolve problemas internos, os quais levam à outra codificação dos gestores internos, que, por sua vez, voltam a integrar uma nova secretaria com perfil também de responsabilidades administrativas essenciais, entre elas, de tesouraria, limpeza e organização.

Vale destacar ainda o caso da cooperativa do assentamento Bela Vista do Chibarro. Entre vários homens, uma personalidade feminina militante passa a ser uma consultora importante para as decisões e articulações do grupo. Esse fato

${ }^{4}$ Entre estas cooperativas, podemos destacar a COOPAM do assentamento Monte Alegre e a COOBELA do assentamento Bela Vista do Chibarro. 
demonstra ainda mais o essencial papel das mulheres nas relações estabelecidas nos assentamentos, especialmente no Bela Vista, onde a história de luta pelo território local tem, nas mulheres, um peso enorme, já que muitas delas foram protagonistas nos movimentos-chave para conquista efetiva dos lotes ${ }^{5}$.

\section{O QUE OS DADOS RELATAM}

A pesquisa foi realizada no assentamento Monte Alegre situado entre cidades de Araraquara, Motuca e Matão, formado por 6 núcleos e 446 lotes, nos quais as mulheres possuem a maior parte da titularidade. $\mathrm{O}$ assentamento encontra-se ainda no coração do plantio de cana-de açúcar do Estado de São Paulo, representando um cinturão agrícola de culturas diversas e um campo possível de análise produtiva quanto a formas mais sustentáveis.

Tal cenário possibilitou que durante as entrevistas, coleta de dados, etnografia, se levantasse questionamentos junto às assentadas sobre conhecimentos em agroecologia, tanto na sua prática, definição ou dos termos desta ciência.

Verificou-se então como a linguagem acadêmica interage, se relaciona, ou constrói entendimentos junto às assentadas.

A perspectiva da Educação do Campo ajuda a refletir sobre estes aspectos, justamente por considerar que os indivíduos fazem parte de um meio, e este é permeado por significados simbólicos e conhecimentos, que devem ser considerados no processo de aprendizagem.

Por exemplo, ao perguntarmos sobre o motivo da participação no curso e se conheciam agroecologia, de todas as entrevistadas, nenhuma afirmou saber a definição do conceito. As respostas variavam entre não saber, não ter ouvido falar, ou ainda, conhecer o que é orgânico ou agroecológico, para alguns é quase uma prática inalcançável, por todos os entraves que se colocam à produção deste tipo de alimento.

O interessante é que apesar da fala, do não conhecimento sobre o que é a agroecologia, muitos deles em seus lotes e práticas diárias a realizam, práticas que se compõem claramente dentro da Agroecologia, sem, no entanto, vincular este saber ao conceito. Um alerta especialmente quando os técnicos ou extensionistas tomam uma postura de desenvolvimento de agroecologia e pensam levar um saber desconhecido para os agricultores (GOMES, 2015). No que se refere a

\footnotetext{
${ }^{5}$ Com relação a este processo, o destaque é para Dona M. R., que veio do Vale do Ribeira para ocupar o território da antiga fazenda Chibarro, que se tornaria o assentamento Bela Vista do Chibarro. Entre as ações desta mulher, encontram-se o enfrentamento direto com a polícia federal em uma ação de despejo, na qual articulou mulheres e crianças para evitar que houvesse tal ato. Outra mulher importante, para citar as relações diretas das mulheres com a luta neste assentamento, é M.A., que deixa a Capital do Estado de São Paulo, largando trabalho na rede Globo emissora e estabilidade, para entrar para a luta da Reforma Agrária, e passa a articular mulheres do Brasil todo junto ao Sindicado dos Trabalhadores Rurais para luta social.
} 
esta concepção inicial, estes técnicos/ extensionistas com esta postura impositiva não estão efetivamente praticando a agroecologia. Já que muitos desconsideram a perspectiva da sustentabilidade e da racionalidade ambiental das relações das comunidades tradicionais, indígenas ou camponesas com o meio como essenciais na conservação da natureza (GOMES, 2015).

As assentadas apresentam práticas e saberes nos quais coexistem elementos da agricultura convencional e conhecimentos tradicionais. Assim, partiu-se do pressuposto de que as práticas/saberes tradicionais das assentadas existem e são elementos do patrimônio imaterial de um grupo que os reconhecem como um saber ligado às práticas sustentáveis em relação à natureza. Portanto, são parte do que a agroecologia sustenta como um conhecimento necessário à vida.

Neste sentido, ao longo das atividades empreendidas neste trabalho, escolhemos fazer um levantamento de receitas e práticas utilizadas pelas assentadas, que foram descritas e discutidas em crescentes convergências, analogias e reconhecimento científico e técnico. Para ilustrar esta discussão, apresentamos o quadro 2 com as principais pragas mais comuns levantadas e as práticas de combate utilizadas pelas mulheres em suas produções.

Verifica-se a existência de práticas sustentáveis misturadas às práticas químicas, que merecem cuidadosamente ser estudadas. No primeiro item do quadro 2, uma das indicações de praga refere-se à mosca branca, inseto muito comum, de ordem dos hemípteros, que no campo geralmente comem e destroem plantas e/ou arbustos, e transmitem doenças. O combate deste inseto é longo, pois sua eliminação pode requerer a aplicação de múltiplos métodos alternados durante várias semanas.

Na prática convencional química, aplica-se, por exemplo, os inseticidas Cartap, Thiobel, Orthene 750BR, mas moscas-brancas desenvolvem uma tolerância a produtos químicos e, por consequência, os agricultores fazem uso destes inseticidas de tipos diferentes em rotação para um controle eficaz. No entanto, o grande problema é que os mesmos levam à morte muitas outras espécies, como as abelhas (GOMES, 2015).

Tal coexistência entre as práticas tradicionais e convencionais na agricultura são aspectos dinâmicos da vida diária do assentado; dada a simbiose da relação com a natureza, que em uma relação dialética entre fazeres tradicionais e usos de inseticidas e pesticidas ressignificam suas práticas na agricultura. A falta de conhecimento apropriado, com relação aos efeitos químicos da agricultura convencional, coloca estes agricultores em uma situação de "analfabetismo", já que muitos acreditam apenas nos efeitos benéficos quanto à maior produtividade. Mesmo diante deste processo, as resistências nas práticas alternativas são identificadas e usadas como 
prática importante no processo diário de cuidado com a produção e a criação (GOMES, 2015).

É importante destacar que muitas das práticas tradicionais já apresentam estudos de correspondência e legitimidade científica. Neste sentido descreveremos a prática e a receita utilizada pelos assentados comparando as possibilidades de usos descritos na literatura científica(Quadro 3).

Quadro 2 - Pragas mais comuns na produção dos assentados.

\begin{tabular}{|l|l|}
\hline Tipo de praga & Método de combate \\
\hline Mosca branca & Urina de vaca curtida, plantar alho e pimenta junto. \\
\hline Lagarta da couve & $\begin{array}{l}\text { Esterco de galinha, porco ou vaca curtido em água du- } \\
\text { rante uma semana. }\end{array}$ \\
\hline Pulgão & Água com sabão, solução de nem \\
\hline Vira-cabeça & Inseticida e fungicida \\
\hline Taquinose & Inseticida e fungicida \\
\hline Cupim/ Broca & Furadam, receita de neem curtido, calda bordalesa \\
\hline Lagarta preta & Calda bordalesa \\
\hline Besouro -vaquinha & $\begin{array}{l}\text { Calda bordalesa, plantar ervas medicinais junto, como } \\
\text { hortelã, boldo, erva cidreira, entre outras. }\end{array}$ \\
\hline Pulgão & $\begin{array}{l}\text { Calda bordalesa, calda de enxofre } \\
\text { detergente calda de cal com }\end{array}$ \\
\hline Fungo & Calda de enxofre \\
\hline $\begin{array}{l}\text { Bicheira, fratura ou } \\
\text { corte }\end{array}$ & Mistura de ervas \\
\hline
\end{tabular}

Fonte: GOMES,2015. 
Quadro 3 - Receitas de práticas tradicionais descritas pelos entrevistados e apresentação na literatura científica.

\begin{tabular}{|c|c|c|}
\hline Nome da Receita & $\begin{array}{l}\text { Receita praticada pelo Assenta- } \\
\text { do (a) }\end{array}$ & $\begin{array}{l}\text { Utilidade da receita apresentada pela Literatura Cien- } \\
\text { tífica }\end{array}$ \\
\hline $\begin{array}{l}\text { Mistura de esterco } \\
\text { curtido }\end{array}$ & $\begin{array}{l}\text { Deixar esterco de galinha, porco } \\
\text { ou vaca curtir na água durante } \\
\text { uma semana. Depois coar e borri- } \\
\text { far nas plantas para fertilização e } \\
\text { combater insetos. }\end{array}$ & $\begin{array}{l}\text { No curtimento ou cura, eliminamos todas as sementes de } \\
\text { ervas espontâneas e também possíveis patógenos ou para- } \\
\text { sitas que possam contaminar os alimentos, e causar pro- } \\
\text { blemas de saúde para os consumidores. Podemos no curti- } \\
\text { mento aumentar a relação Carbono/Nitrogênio do esterco, } \\
\text { colocando palhas ou material rico em celulose. Podemos } \\
\text { trabalhar com } 3 \text { a } 5 \text { partes de material rico em celulose } \\
\text { para cada parte de esterco }\end{array}$ \\
\hline Urina de vaca: & $\begin{array}{l}\text { Curtir a urina com água. Colocar } \\
\text { nas plantas para fortalecer e es- } \\
\text { pantar insetos. }\end{array}$ & $\begin{array}{l}\text { Nutre corretamente a planta, aumentando o número de bro- } \\
\text { tações, de folhas, de flores e da produtividade. "As plantas } \\
\text { ficam saudáveis e mais resistentes às pragas e doenças. É } \\
\text { a possibilidade de o produtor utilizar, regularmente, uma } \\
\text { adubação completa. De acordo com os estudos desenvol- } \\
\text { vidos até o momento, as principais substâncias encontra- } \\
\text { das na urina de vaca são: nitrogênio, fósforo, potássio, } \\
\text { cálcio, magnésio, enxofre, ferro, manganês, boro, cobre, } \\
\text { zinco, sódio, cloro, cobalto, molibdênio, alumínio (abaixo } \\
\text { de } 0,1 \text { ppm), fenóis (aumentam a resistência das plantas) } \\
\text { e ácido indolacético (hormônio natural de crescimento)"6. }\end{array}$ \\
\hline Calda de enxofre & $\begin{array}{l}\text { Usa-se esterco de vaca, folhas de } \\
\text { mamona, calcário } 2001 \text { de enxofre } \\
\text { diluídos em água. Aqui, o assen- } \\
\text { tado faz suas adaptações segundo } \\
\text { sua prática diária, modifica o seu } \\
\text { nome e parte dos ingredientes, } \\
\text { transformando a tradicional calda } \\
\text { bordalesa em calda de enxofre. }\end{array}$ & $\begin{array}{l}\text { Para proteger plantas do ataque de fungos e ácaros, prepa- } \\
\text { re em casa a calda bordalesa. }\end{array}$ \\
\hline Neem curtido & $\begin{array}{l}\text { Sementes ou folhas de nem tritu- } \\
\text { radas, curtidas em água e/ou no } \\
\text { álcool para matar cupim, broca, } \\
\text { pulgão. }\end{array}$ & $\begin{array}{l}\text { Inseticida vegetal que combate mais de } 100 \text { tipos de in- } \\
\text { setos como mosca branca, mosca do gado, cochonilha, } \\
\text { pulgão, lagartas. Também é utilizado como carrapaticida } \\
\text { e combate vermes em animais? . Verifica-se que a utiliza- } \\
\text { ção do neem é muito mais ampla do que o proposto pelos } \\
\text { assentados. }\end{array}$ \\
\hline Calda bordalesa & $\begin{array}{l}\text { Misturar } 10 \text { litros de água com cal } \\
\text { virgem com sulfato cúprico. }\end{array}$ & $\begin{array}{l}\text { Dissolver em } 10 \text { litros de água, } 100 \mathrm{~g} \text { de cal virgem e } 100 \mathrm{~g} \\
\text { de sulfato de cobre. A calda é recomendada para o controle } \\
\text { de doenças e parasitas, de míldio e alternaria de hortaliças } \\
\text { e legumes com a couve, repolho, chuchu, a antracnose do } \\
\text { feijão, pinta preta e queima do tomate, murchadeira da ba- } \\
\text { tata, queima das folhas da cenoura. Também é utilizada } \\
\text { em frutíferas. }\end{array}$ \\
\hline
\end{tabular}

Fonte: GOMES,2015.

\footnotetext{
${ }^{6}$ Ver receita, orientação do site: http://www.pesagro.rj.gov.br/urina.html

${ }^{7}$ Fonte: http://www.caatinga.org.br/wp-content/uploads/2014/03/NIM-IX.pdf-cartilha-do-caatinga.pdf
} 
Além destas práticas tradicionais, incluem-se utilizações de mistura de ervas, que se destacam como conjuntos dos saberes ricos, mas difíceis de serem registrados, dado ao fato de se referirem, especialmente, à experiência diária de cada assentado e assentada. Estas técnicas se constroem através da observação e análise dos resultados cotidianos da interação com a natureza e representam, para agroecologia, um elemento fundamental que é a conservação da biodiversidade.

Dentre as possibilidades pontuadas sobre a associação da biodiversidade às produções, destacaram-se dois usos que nos chamaram mais a atenção. O primeiro deles é quanto aos lotes de assentados que declararam não utilizar nenhum tipo de veneno, apenas técnicas de controle de pragas naturais como biofetilizantes e/ ou ervas consorciadas nos canteiros de horta. Nestes lotes, além das técnicas, a quantidade de biodiversidade, tanto na conservação das matas ciliares quanto dentro do lote, foi superior a todos os lotes visitados ao longo da pesquisa (GOMES, 2015).

Vale acrescentar aqui a correlação entre biodiversidade e práticas ecológicas, no conjunto de seres vivos. Entre eles, borboletas, aranhas, formigas, besouros, pássaros, dentre outros. Mostram-se como indicativo de equilíbrio, do meio ajudando na harmonização das condições ambientais. Fato este, decorrente do controle ambiental e polinização promovida quando os inimigos naturais e alguns insetos deixam de ser pragas e encontram-se em equilíbrio.

O segundo ponto é o uso das plantas ou ervas medicinais como métodos antipragas, fungicidas e curativos que, entre as mulheres, encontramos a grande fonte deste conhecimento. Verifica-se que a maior parte das ervas descritas por estas mulheres participantes da pesquisa estão regulamentadas pela ANVISA- Agência Nacional de Vigilância Sanitária ${ }^{8}$ por meio de resolução RDC No 10 , de 9 de março de 2010, e são inclusive indicadas como medicamentos complementares aos alopáticos. Segundo esta resolução, compreende-se:

"o produto que deve ser designado de "Chá", seguido do nome comum da espécie vegetal utilizada, podendo ser acrescido do processo de obtenção e ou característica específica. Podem ser utilizadas denominações consagradas pelo uso" (RDC No10/2010).

Além da listagem das 66 de ervas foram levantados outros tipos de ervas, que não estavam nesta listagem, mas dos quais há um amplo uso na prática popular e até na literatura científica, embora ainda não tenham sido acrescentados à listagem de interesse do SUS segundo a ANVISA. Abaixo se encontra a tabela de listagem das ervas encontradas nos lotes das mulheres (Tabela 1).

\footnotetext{
${ }^{8}$ Fonte: http://bvsms.saude.gov.br/bvs/saudelegis/anvisa/2010/res0010_09_03_2010.html
} 


\section{Tabela 1 - Listagem das ervas da ANVISA segundo RDC n ${ }^{\circ} 10$ encontradas nos lotes inventariados.}

\begin{tabular}{|c|c|c|}
\hline Ervas regulamentadas pela ANVISA & $\begin{array}{c}\text { Número de } \\
\text { lotes com as } \\
\text { ervas }\end{array}$ & $\begin{array}{l}\text { Porcentagem de lotes que pro- } \\
\text { duzem as ervas } \%\end{array}$ \\
\hline Alecrim - Rosmarinus officinalis & 10 & 62,5 \\
\hline Alho - Allium sativum & 4 & 25 \\
\hline Anis estrelado - Illicium verum & 2 & 12,5 \\
\hline Anis, Erva doce - Pimpinela anisum & 3 & 18,75 \\
\hline Arnica - Arnica montana & 5 & 31,25 \\
\hline Aroeira da praia - Schinus terebinthifolia & 2 & 12,5 \\
\hline Assa peixe - Vernonia polyanthes & 2 & 12,5 \\
\hline Barbatimão - Stryphnoden dromadstrigens & 5 & 31,25 \\
\hline Boldo do chile - Peumus boldus & 8 & 50 \\
\hline $\begin{array}{l}\text { Boldo nacional, Hortelã homem, Falso boldo, Boldo africano } \\
\text { - Plectranthus barbatus }\end{array}$ & 6 & 37,5 \\
\hline Cajueiro - Anacardium occidentale & 6 & 37,5 \\
\hline Canela - Cinnamomum verum & 2 & 12,5 \\
\hline $\begin{array}{l}\text { Capim santo, Capim limão, Capim cidreira, Cidreira - Cym- } \\
\text { bopogon citratus }\end{array}$ & 11 & 68,75 \\
\hline Cavalinha-Equisetum arvense & 2 & 12,5 \\
\hline Chapéu de couro - Echinodorus macrophyllus & 2 & 12,5 \\
\hline Curcuma, Açafrão da Terra - Curcuma longa & 4 & 25 \\
\hline Dente de leão-Taraxacum officinale & 3 & 18,75 \\
\hline Erva cidreira, Falsa melissa - Lippia alba & 12 & 75 \\
\hline Erva de bicho, Pimenteira dágua - Polygonum punctatum & 1 & 6,25 \\
\hline Eucalipto - Eucalyptus globulus & 8 & 50 \\
\hline Gengibre - Zingiber officinale & 7 & 43,75 \\
\hline Goiabeira - Psidium guajava & 13 & 81,25 \\
\hline Guaco-Mikania glomerata & 2 & 12,5 \\
\hline Guaraná - Paullinia cupana & 1 & 6,25 \\
\hline Hortelã pimenta - Mentha x piperita & 11 & 68,75 \\
\hline Jucá, Pau ferro - Caesalpinia ferrea & 1 & 6,25 \\
\hline Jurubeba - Solanum paniculatum & 7 & 43,75 \\
\hline Laranja amarga - Citrus aurantium & 3 & 18,75 \\
\hline Macela, Marcela - Achyrocline satureioides & 4 & 25 \\
\hline Maracujá - Passiflora alata & 11 & 68,75 \\
\hline Maracujá azedo - Passiflora edulis & 6 & 37,5 \\
\hline Melão de São Caetano - Momordica charantia & 7 & 43,75 \\
\hline Melissa, Erva cidreira - Melissa officinalis & 3 & 18,75 \\
\hline
\end{tabular}


Tabela 1 - Listagem das ervas da ANVISA segundo RDC nº 10 encontradas nos lotes inventariados (cont.).

\begin{tabular}{lcc}
\hline Mentrasto, Catinga de bode - Ageratum conyzoides & 8 & 50 \\
\hline Picão - Bidens pilosa & 13 & 81,25 \\
\hline Pitangueira - Eugenia uniflora & 6 & 37,5 \\
\hline Poejo - Mentha pulegium & 1 & 6,25 \\
\hline Quebra pedra - Phyllanthus niruri & 10 & 62,5 \\
\hline Romã - Punica granatum & 10 & 62,5 \\
\hline Sabugueiro - Sambucus nigra & 2 & 12,5 \\
\hline
\end{tabular}

Fonte: (GOMES, 2018).

É possível verificar que seja na produção agrícola, na produção de medicamentos ou técnicas alternativas de combates às pragas, a todo o momento há resgate de sentimentos de permanência e resistência das práticas tradicionais, mesmo frente à ofensiva da agricultura convencional. À medida em que os princípios da Revolução Verde avançam, encontram-se vários caminhos criativos de convivência para resgate destas práticas, ressignificadas pelas novas gerações, que dão o tom da permanência cultural e patrimonial ao grupo local. Sobre esta simbiose o assentado incorpora técnicas da agricultura convencional à tradicional, como resultado da realidade, das dificuldades, daquilo que eles têm disponível para resolver seus problemas de produção e essencialmente de sua experiência vivida.

Tais pontos nos levam a refletir sobre os processos de transição agroecológica, no sentido de respeitar o tempo, e a perspectiva do assentado sobre o que ele quer e deseja para seu futuro. Não basta existir políticas e pessoas capacitadas para realizar a transição, se não houver agentes que desejem promover a mudança. Por isso, trata-se de um processo de idas e vindas, de integração e espera, exatamente como nos agroecosssistemas, em que a simbiose e a interligação levam tempo para a ocorrência do equilíbrio ecológico. E, nem sempre as técnicas funcionam de imediato, estabelecendo desafios para a extensão agroecológica e a formulação técnico-científica frente às demandas objetivas dos assentados em produzir e gerar renda. Mas, sem dúvidas, no processo de co-educação estas passam a ser recebidos e valorizados como conhecimentos ecológicos e sustentáveis, indispensáveis para manutenção da vida e das espécies ligadas aos modos de vida das populações rurais.

\section{Conclusões}

Parte de toda esta diversidade se faz pela valorização de conhecimentos advindos hereditariamente, em que se usava um chá ou um tipo de alimento de outra região 
do país e no embolado de espécies se conservam como práticas cotidianas e saberes tradicionais. A valorização que acompanhamos a partir do processo de co-educação destas mulheres nos mostrou que a vida é aqui entendida com proporções ainda maiores do que apenas a saúde individual, pois esta se faz através da relação universal de efeitos tão abrangentes que afetam não unicamente o corpo humano, mas as diferentes espécies, o clima e a própria relação com a natureza e com as culturas tradicionais e agrícolas.

$\mathrm{Na}$ experiência das capacitações, destaca-se que o processo de co-educação, re-edução, de relembrar e reavivar os olhares, os cursos puderam trazer, ao mesmo tempo, práticas/saberes agroecológicos, utilizados desde sempre pelos assentados que são reafirmados positivamente e socializados e ainda o aprendizado para novas práticas sustentáveis com relação à não utilização de agroquímicos.

A partir disso, os saberes tradicionais e os conhecimentos adquiridos de forma geracional com o vivenciamento intuitivo a partir da observação da natureza, predominante nas atividades femininas, são substituídos por práticas artificializadas e sintéticas, no caso da produção comercial. Neste aspecto, o papel feminino é duplamente importante, primeiro por serem as mulheres, em grande medida, responsáveis pela permanência da resistência de práticas alternativas frente ao sistema da agricultura convencional e, segundo, por manterem vivos e repassarem um conhecimento sobre saúde, criação e meio ambiente mais sustentável às novas gerações.

Muitas das práticas naturais que a ciência tem chamado de Agroecologia e praticado em quintais, áreas da agrovila, pomares, sítios, hortinhas têm novamente a figura feminina como ponto central na sua organização e cuidado.

\section{REFERÊNCIAS}

ACAYABA, R. D. Ocorrência de agrotóxicos usados na cana-de-açúcar em corpos d'água no Estado de São Paulo. (Dissertação de mestrado). Campinas: UNICAMP, 2017.

ALTIERI, M. A. Agroecologia: bases científicas para uma agricultura sustentável. São Paulo: Expressão Popular, 2012.

ALTIERI, M. A; NICHOLlS, C. Agroecologia: Teoria y prática para uma agricultura sustentable. México: Pnuma y red de formación ambiental para América latina y El Caribe, 2000. 
ANVISA. Disponível em: <http://bvsms.saude.gov.br/bvs/saudelegis/anvisa/2010/ res0010_09_03_2010.html > acesso: 26. set. 2019.

BRASIL. Resolução de Diretoria Colegiada (RDC) no 10 de 09 de março de 2010. Notificação de drogas vegetais. Agência Nacional de Vigilância Sanitária -ANVISA. Brasília: Diário Oficial da União, 2010.

BRASIL. Resolução de Diretoria Colegiada (RDC) no 10 de 09 de março de 2010. Notificação de drogas vegetais. Agência Nacional de Vigilância Sanitária -ANVISA. Brasília: Diário Oficial da União, 2010.

CAATINGA. Disponível em: < http://www.caatinga.org.br/wp-content/ uploads/2014/03/NIM-IX.pdf-cartilha-do-caatinga.pdf > acesso: 26. set. 2019.

CAPORAL, F. R. Bases para uma nova Ater pública.1998. Disponível em: https://www.agencia.cnptia.embrapa.br/recursos/AterPublicaID-JdUuogQPhM. pdf. Acesso em: set. 2018.

CAPORAL, F. R.; COSTABABER, J. A. Agroecologia: uma ciência do campo e da complexidade. Brasília, DF: 2009.

CASTANHO FILHO, E. P.; CHABARIBERY, D. Perfil energético da agricultura paulista. Agricultura em São Paulo, São Paulo, v. 30, t. I-II, p. 63-115, 1983.

COSTA, M. B. B. Análise da sustentabilidade da agricultura da região metropolitanda de Curitiba, pela ótica da agroecologia. Tese de Doutorado. Curitiba: UFPR, 2004.

DOERING III, O. C. An energy-based analysis of alternative production methods and cropping systems in Corn Belt. Purdue University, Agriculture Experimente Station, 1977.

FERMENT, G. et al. Lavouras transgênicas Riscos e incertezas. Brasília, DF: MDA, 2015.

FERNANDES, G.B.; FERRAZ, J. M. G.; MELGAREJO, L. Dez anos de transgênicos no Brasil. In: Seminário Internacional 10 anos de transgênicos no 
Brasil, 2009. Disponível em: <http://aspta.org.br/wp-content/uploads/2013/10/ Texto-10-anos-Transg\%C3\%AAnicos.pdf $>$. Acesso em: jan. 2017.

GASTAL, M. L. et al. Método participativo de apoio ao desenvolvimento sustentável de assentamentos de reforma agrária. Planaltina, DF: Embrapa Cerrados, 2002.

GLIESSMAN, S. R. Agroecologia: Processos Ecológicos em Agricultura Sustentável. Porto Alegre: UFRGS, 2000.

GOMES, T. P. de S. O multiculturalismo, movimentos sociais e educação do campo. In: VII Jornada de Estudos em Assentamentos Rurais, 2015, Campinas. Anais. VII Jornada de Estudos em Assentamentos Rurais, 2015.

. Do sonho à realidade: um estudo da trajetória de mulheres assentadas na constituição de práticas agroecológicas através do resgate de saberes tradicionais. Tese de Doutorado. Araraquara: UNESP, 2018.

. Educação - Finalidades e objetivos. Educação não formalLondrina: Editora e Distribuidora Educacional S.A., 2017.

. Entre canteiros e ervas: um estudo da produção de ervas medicinais a partir de indicação do interesse do SUS- Sistema Único de Saúde. Araraquara, ReBraM, v23, n2, 2019(prelo).

KAGEYAMA, P. Transgênicos e Biodiversidade. In: REUNIÃO ANUAL DA SBPC, 61., Manaus, AM. Anais... 2009. Disponível em: FERNANDES et al 2013

KUMMER, L. Metodologia participativa no meio rural: uma visão interdisciplinar. conceitos, ferramentas e vivências. Salvador: GTZ, 2007.

NúCleo de estudos E eXTensão em AgRoeCologia (NEEA). Pesquisa-ação e construção de proposta agroecológica para a agricultura familiar da região central do estado de São Paulo. (Relatório Técnico). Araraquara: Universidade de Araraquara, 2017. 
PENTEADO, S. R. Controle alternativo de pragas e doenças com as caldas bordalesa, sulfocálcica e Viçosa. Campinas: Buena Mendes Gráfica e Editora, 2000. 95p.

PIMENTEL, D. Produção de alimentos e crise energética. EMPASC, 1982.

QUEDA, O.; KAGEYAMA, P. Y.; SANTOS, J. D. Assentamentos rurais: alternativas frente ao agronegócio. Retratos de Assentamentos, n. 12, p. 47-68, 2009.

RAPPAPORT, R. A. The sacred human evolution. Anual Review of Ecology and Systematics, v. 2:23-44, 1971.

SEVILLA GUZMÁN, E. Agroecología y desarrollo rural sustentable: una propuesta desde Latinoamérica. In: Agroecología: El camino hacia una agricultura sustentable (Sarandón S, ed.). Buenos Aires-LaPlata: Ediciones Científicas Americanas, pp. 57-81. 